\title{
SISTEM INFORMASI EXPEDISI PENGIRIMAN BARANG PADA BAGIAN DISTRIBUSI PT. TEMPO BANDA ACEH
}

\author{
M. Ikram \\ Mahasiswa Program Studi Manajemen Informatika, Fakultas Ilmu Komputer, \\ AMIK Indonesia, Jl. T Nyak Arief Sp Mesra No. 400, Kota Banda Aceh, Indonesia \\ Email: m.iktam_aceh@gmail.com
}

\begin{abstract}
Abstrak
Tujuan penelitian yaitu untuk mengetahui dan merancang Sistem Informasi Expedisi Pengiriman Barang pada Bagian Distribusi PT. Tempo Banda Aceh dengan bahasa pemrograman HTML, PHP, CSS, JSON, AJAX dan MySQL sebagai pendukung database. Secara garis besar penelitian ini dibagi dalam tiga tahapan, yaitu pengumpulan data pra pengembangan, pengembangan serta implementasi, dan pengumpulan data pasca Pengembangan. Sedangkan dalam pengembangan perangkat lunak menggunakan metode Agile. Dari hasil penelitian dapat disimpulkan bahwa Sistem informasi ekspedisi pengiriman barang pada PT. Tempo Banda Aceh sudah mengikuti prosedur dengan menggunakan bahasa pemrograman HTML, PHP, CSS, JSON, AJAX dan MySQL sebagai pendukung database.
\end{abstract}

Kata Kunci: Sistem Informasi; Expedis;I Pengiriman Barang; Distribusi; PT. Tempo Banda Aceh.

\begin{abstract}
The purpose of this research is to find out and design a Freight Forwarding Expedition Information System at the Distribution Section of PT. Tempo Banda Aceh with HTML, PHP, CSS, JSON, AJAX and MySQL programming languages as database support. Broadly speaking, this research is divided into three stages, namely pre-development data collection, development and implementation, and post-development data collection. While in software development using the Agile method. From the results of the study it can be concluded that the information system for shipping freight forwarders at PT. Tempo Banda Aceh has followed the procedure using HTML, PHP, CSS, JSON, AJAX and MySQL programming languages as database support.
\end{abstract}

Keyword: Information Systems; Expedition; Distribution; PT. Tempo Banda Aceh. 


\section{Pendahuluan}

Pada beberapa tahun terakhir ini, kemajuan teknologi dalam bidang informasi dan komunikasi berkembang pesat [1,2]. Banyak perusahaan-perusahaan yang sudah menggunakan teknologi informasi dan komunikasi sebagai alat bantu dalam menjalankan operasinya diperusahaan [3,4]. Namun tidak sedikit juga perusahaan yang masih belum menggunakan teknologi informasi dan komunikasi secara maksimal [5,6]. Perkembangan jasa ekspedisi sekarang mulai berkembang dengan pesat, masih banyak juga jasa ekspedisi melakukan sistem penginputannya dengan manual [7], Disertai dengan pekembangan aplikasi yang baik [8,9], tidak heran banyak sekali bermunculan para pengembang baru yang membuat berbagai aplikasi pendukung piranti pintar [10,11].

PT. Tempo Banda Aceh adalah sebuah perusahaan yang bergerak dibidang jasa pengiriman barang jalur darat di Aceh. PT. Tempo Banda Aceh didalam proses bisnisnya merupakan rekanan kerja dari beberapa pelanggan yang berlokasi di Banda Aceh. Rekanan kerja PT. Tempo Banda Aceh juga merupakan ekspedisi-ekspedisi yang ada di seluruh Indonesia. Pengiriman-pengiriman yang dilakukan rekan PT. Tempo Banda Aceh di Jakarta melalui jalur udara dengan maskapai penerbangan Lion Air, Garuda Indonesia atau Air Asia. Di dalam proses bisnis ini, PT. Tempo Banda Aceh tidak terlepas dari kendala yang dihadapi, seperti belum adanya informasi pengingat dan pengaturan untuk pengambilan barang di bandara yang menyebabkan keterlambatan dalam pengambilan barang, tidak ada pengaturan pengiriman yang sifatnya urgent, kesulitan dalam mencari tahu informasi barang yang diangkut oleh sebuah kendaraan, pencatatan informasi data barang dan pelanggan yang terduplikasi.

Sehubung dengan permasalahan tesebut, peneliti ingin membantu menyelesaikan permasalahan yang dihadapi perusahaan dengan membangun sistem informasi sebagai teknologi informasi untuk menyelesaikan masalah yang ada seperti pengaturan informasi pengangkutan barang dengan memberikan informasi rute-rute. Pengingat untuk pengambilan barang dibandara berdasarkan jam penerbangan pesawat. Selain itu pengontrolan untuk barang-barang yang sudah diambil atau belum dan memberikan pengingat untuk barang-barang yang belum diambil. Kemudian dibuat fitur pemilahan barang-barang yang sifatnya urgent agar dapat diantarkan terlebih dahulu. Memberikan fitur tracking barang untuk bagian administrasi ataupun bagian gudang agar dapat mengetahui lokasi barang pada kendaraan yang mana ketika dalam proses pengiriman. Dari uraian tersebut maka yang menjadi tujuan penelitian yaitu untuk mengetahui dan merancang Sistem Informasi Expedisi Pengiriman Barang pada Bagian Distribusi PT. Tempo Banda Aceh dengan bahasa pemrograman HTML, PHP, CSS, JSON, AJAX dan MySQL sebagai pendukung database.

\section{Metode Penelitian}

Pengumpulan data yang diperlukan dalam penulisan penelitian ini diperoleh dengan dua metode yaitu studi kepustakaan yang berkaitan dengan literatur-literatur buku-buku perpustakaan dan karya ilmiah lainnya [12,13], studi lapangan dengan melaksanakan interview dan observasi langsung terhadap objek yang berhubungan dengan penelitian ini [14]. Secara garis besar penelitian ini dibagi dalam tiga tahapan, yaitu pengumpulan data pra Pengembangan $[15,16]$, pengembangan serta implementasi, dan pengumpulan data pasca Pengembangan [17]. Sedangkan dalam pengembangan perangkat lunak menggunakan metode agile yang ditujukan untuk menangani munculnya berbagai variabel dan kekompleksan yang mungkin terjadi dalam pengembangan sebuah proyek $[18,19,20]$. Adapun penjelasan detail untuk tahapan penelitian adalah seperti dijelaskan pada gambar 1 berikut. 


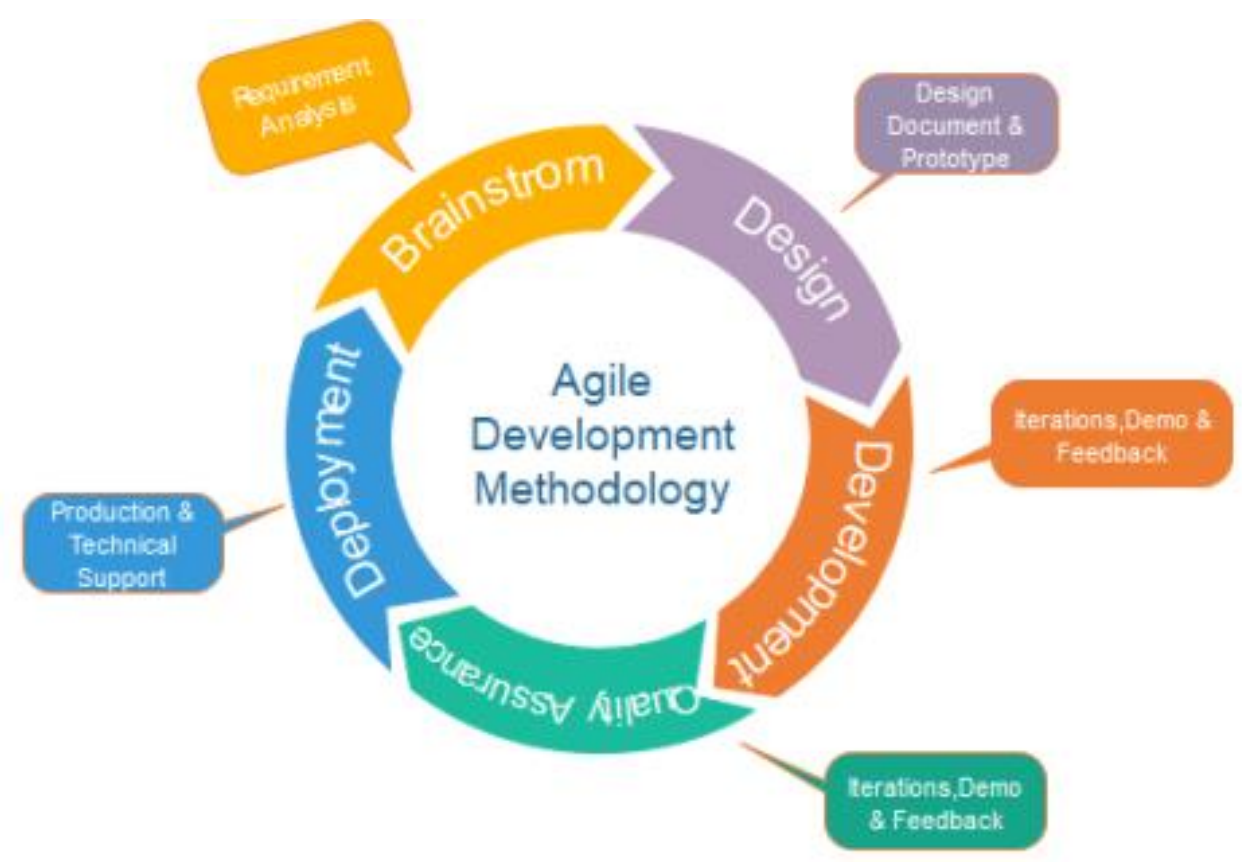

Gambar 1. Metode Agile.

\section{Hasil dan Pembahasan}

Sistem yang akan dibangun adalah suatu sistem yang memanfaatkan komputer sebagai perangkat utama pemrosesan. Manusia bertindak sebagai pengatur, pengoperasi, serta pengendali utama perangkat tersebut. Cara kerja sistem baru merupakan suatu pengembangan dari cara kerja sistem yang lama. Sistem informasi yang dibangun ini nantinya diharapkan mampu mempersingkat waktu dalam menghasilkan laporan rekap biaya dan rekap ekspedisi pengiriman barang. Serta membuat penyimpanan dan pengelolaan ekspedisi pengiriman barang menjadi lebih terstruktur lagi. Ada tiga tahapan utama dalam sistem informasi ekspedisi ini, yaitu input data, proses dan data keluaran.

Data yang dikelola pada sistem yang berjalan saat ini tidaklah sistematis, dimana data yang dimiliki tidak dapat mendeskripsikan data secara unik. Melihat kondisi data yang diolah oleh sistem saat ini perlu adanya pembuatan sistem pengkodean data, sehingga beberapa data yang sama jenisnya dapat dikenali sebagai suatau objek yang diinginkan. Dalam proses pengolahan data rekap ekspedisi pengiriman barang pada PT. Tempo sudah menggunakan sistem yang terkomputerisasi dengan menggunakan aplikasi standar seperti Microsoft Office Excell, tetapi kendala juga sering terjadi akibat pengulangan pengisian data yang berulang dalam menentukan penyimpanan data perhari sehingga prosesnya terkesan lambat. Dan proses pembuatan laporan pun kadang terjadi kesalahan dan kadang mengalami keterlambatan penyampaian kepada pihak-pihak yang bersangkutan.

\section{Analisa Masukan}

Analisis masukan merupakan data yang masuk kedalam system informasi. Komponen ini perlu ada karena merupakan bahan dasar dalam pengolahan data, adapun data-data tersebut adalah :
a) Nama Penerima;
b) Alamat;
c) Nama Barang;
d) Berat;
e) Tinggi;
f) Jenis; 
g) Tipe Pengiriman,

h) Supir,

i) Pengangkutan, dan

j) Keterangan.

\section{Struktur Menu Program}

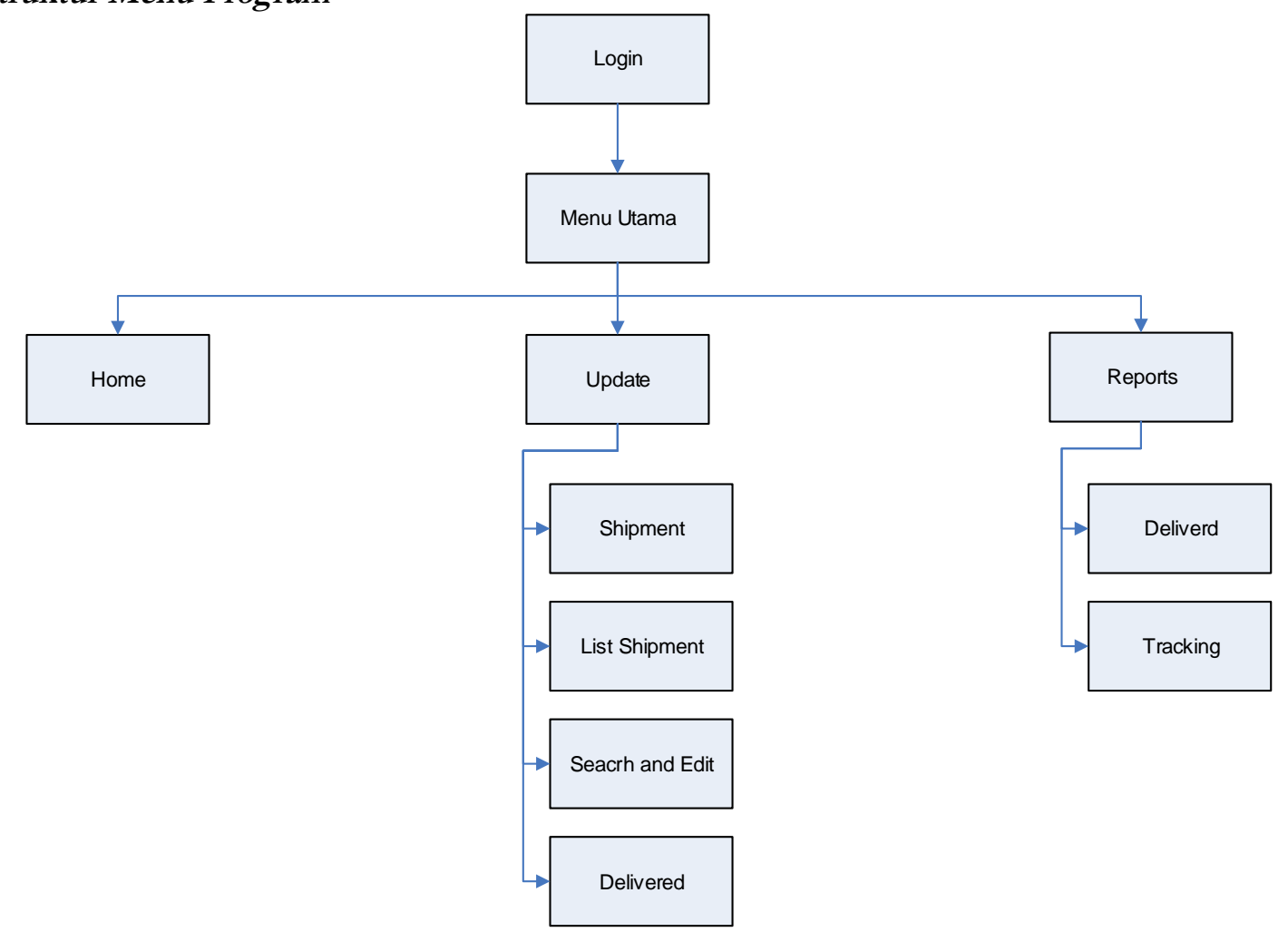

Gambar 2. Struktur Menu Admin

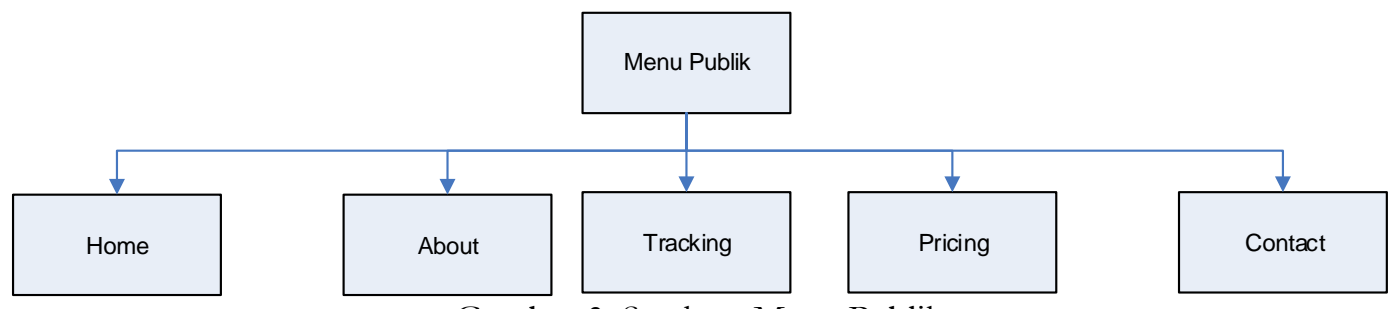

Gambar 3. Struktur Menu Publik

\section{Hasil Perancangan}

Adapun hasil dari perancangan terdiri dari; Form Login, Menu Utama Admin, Input Office Manager, Input Manager, Input Ekspedisi, dan Pencarian Tracking Barang. 


\section{Jurnal Indonesia : Manajemen Informatika dan Komunikasi}

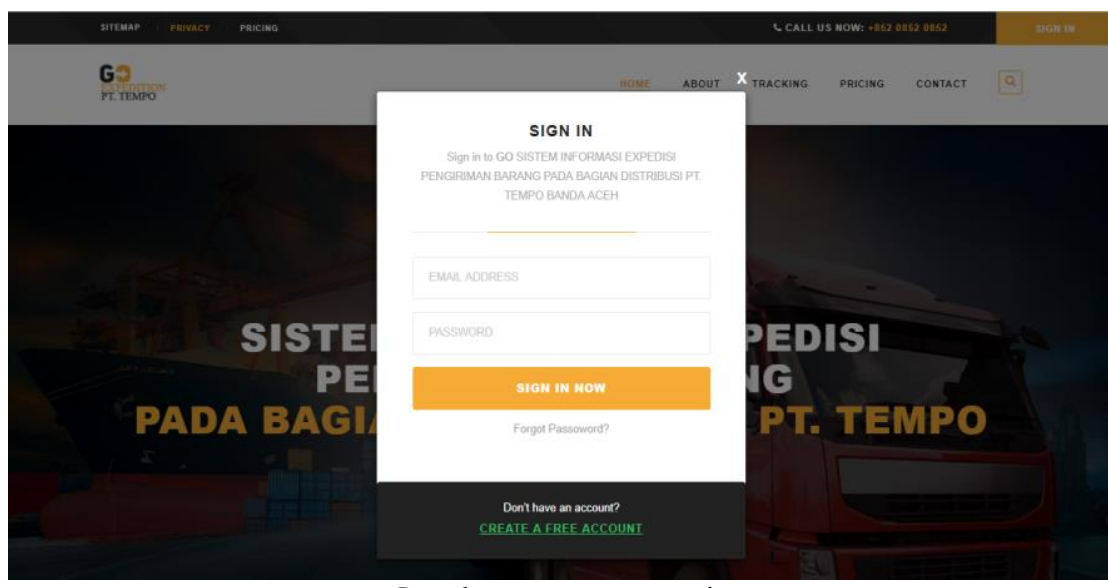

Gambar 4. Form Login

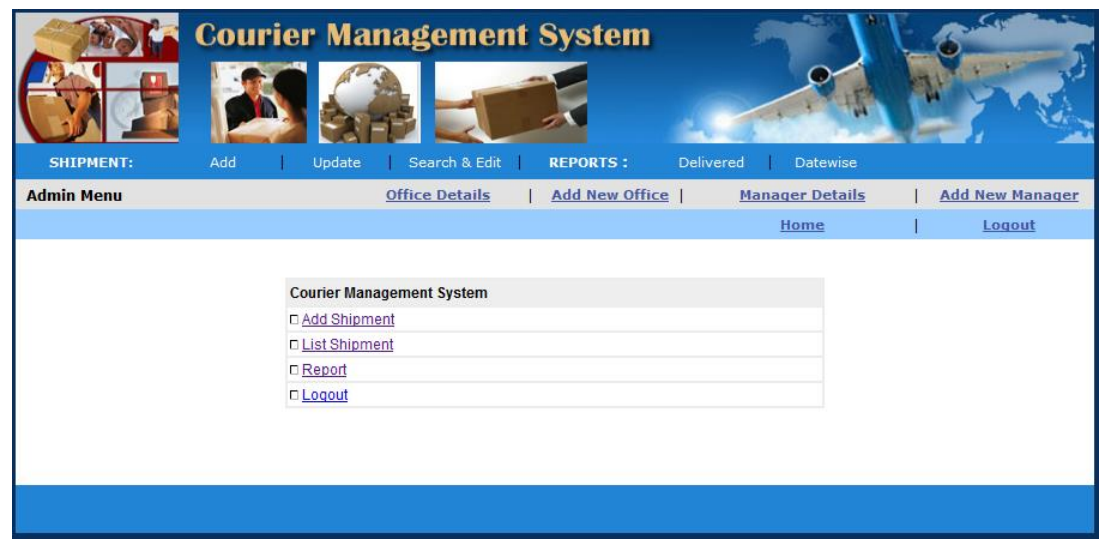

Gambar 5. Form Menu Utama Admin

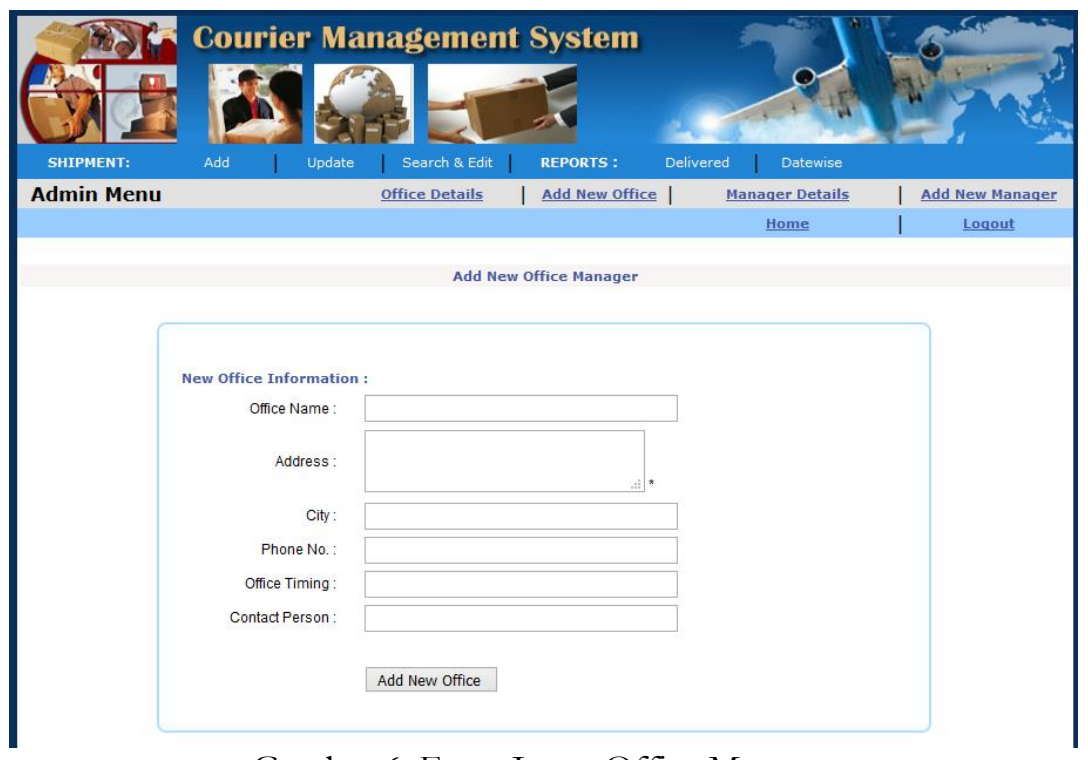

Gambar 6. Form Input Office Manager 


\section{Jurnal Indonesia : Manajemen Informatika dan Komunikasi}

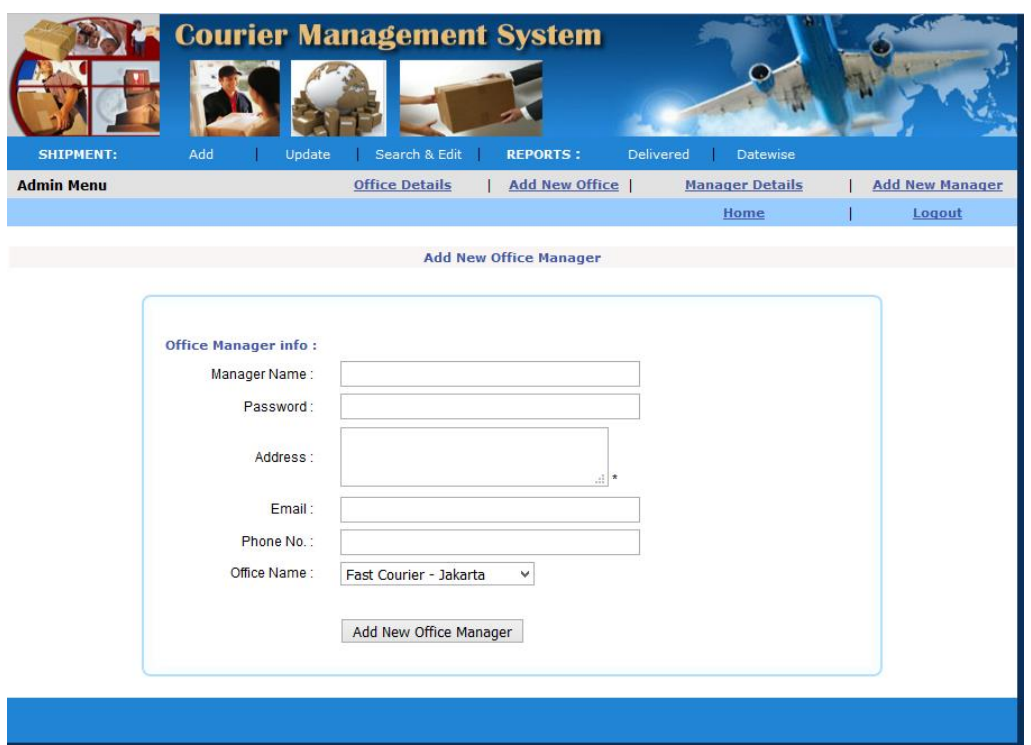

Gambar 7. Form Input Manager

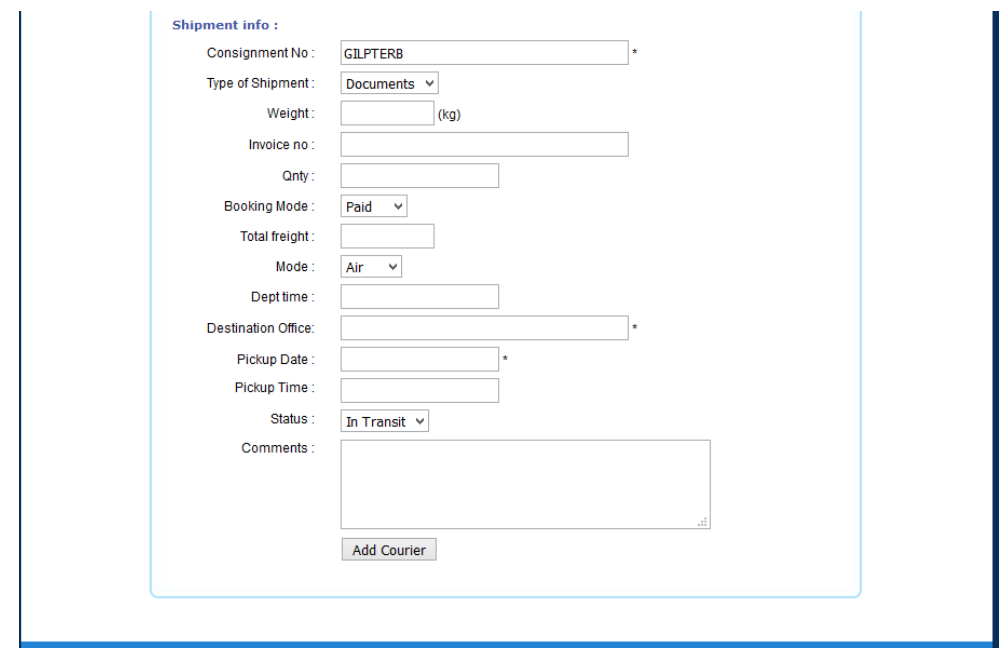

Gambar 8. Form Input Ekspedisi

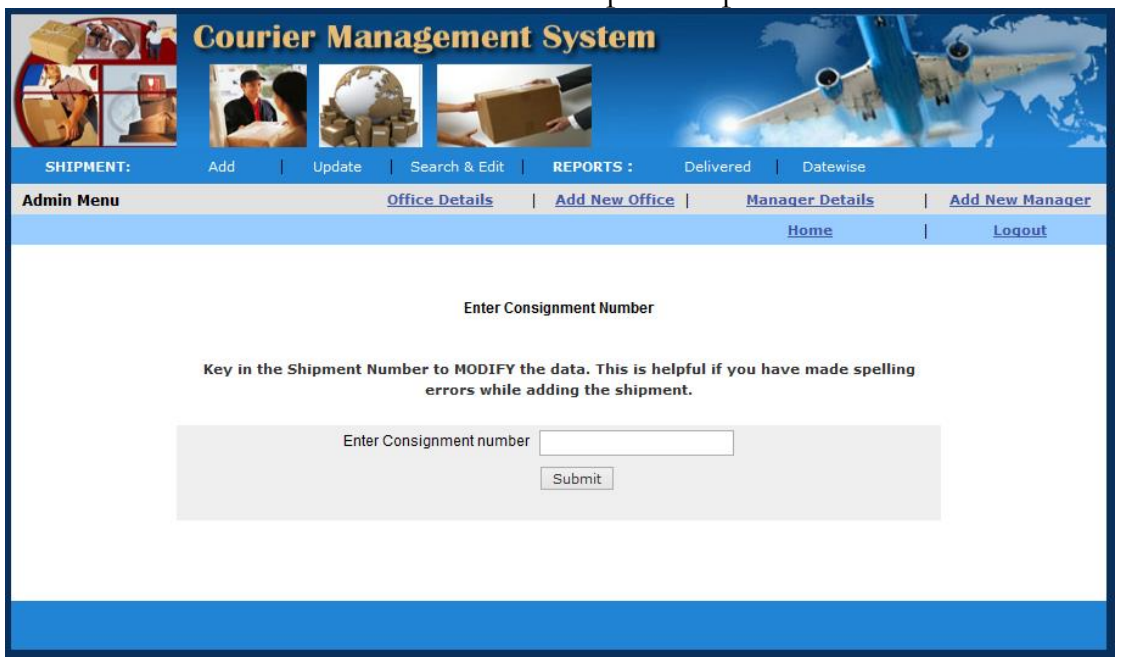

Gambar 9. Form Pencarian Tracking Barang 


\section{Jurnal Indonesia : Manajemen Informatika dan Komunikasi}

Adapun hasil dari keluaran aplikasi berupa; Laporan Daftar Ekspedisi, Laporan Update Ekspedisi, Laporan Manager, dan Publik.

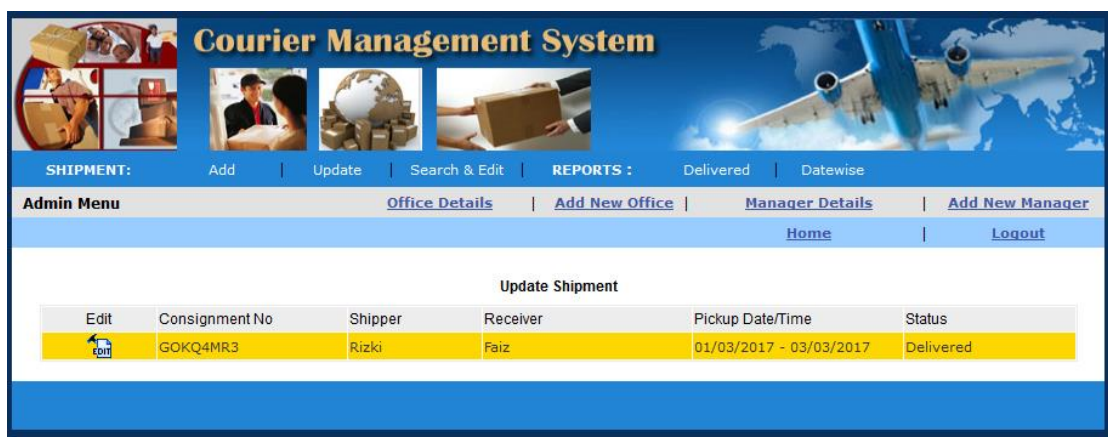

Gambar 10. Form Laporan Daftar Ekspedisi

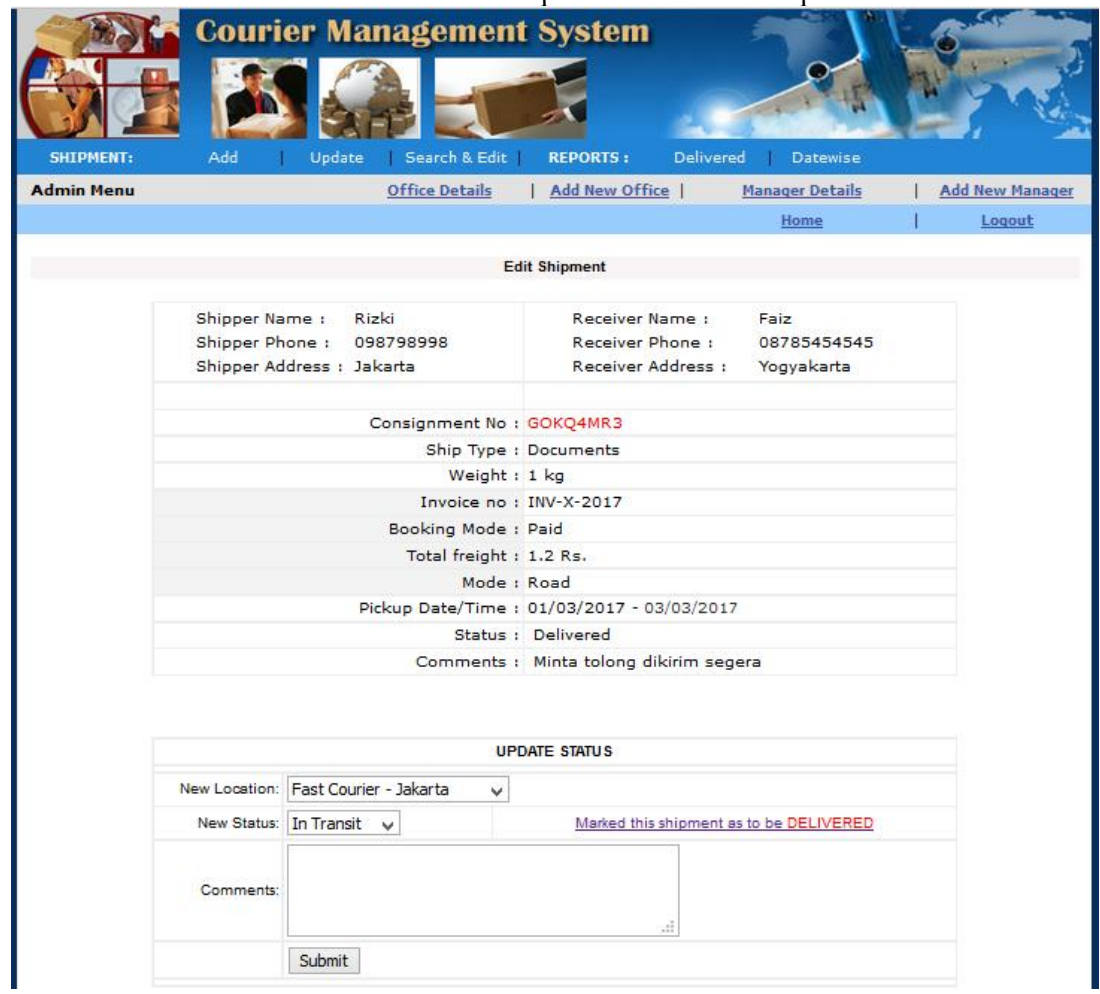

Gambar 11. Form Laporan Update Ekspedisi

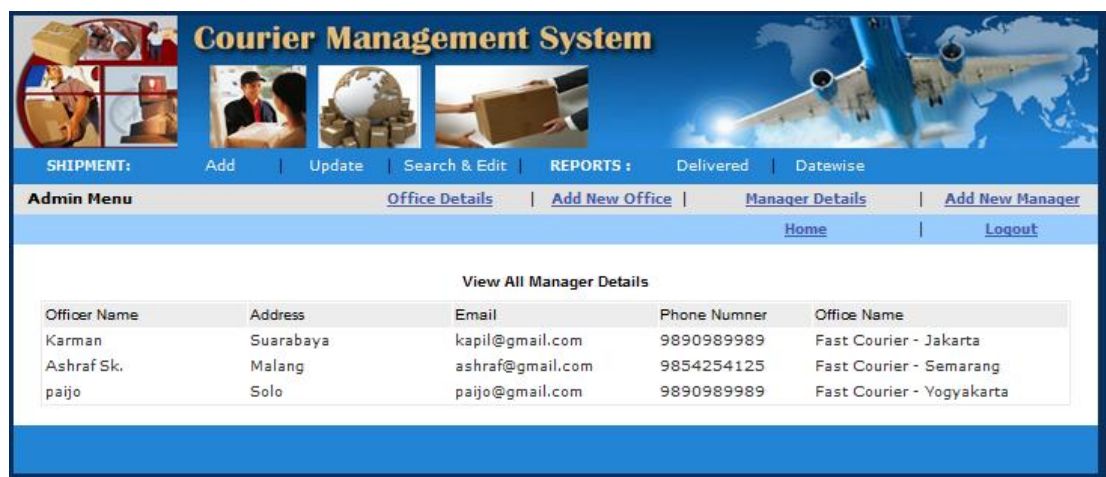

Gambar 12. Form Laporan Manager 


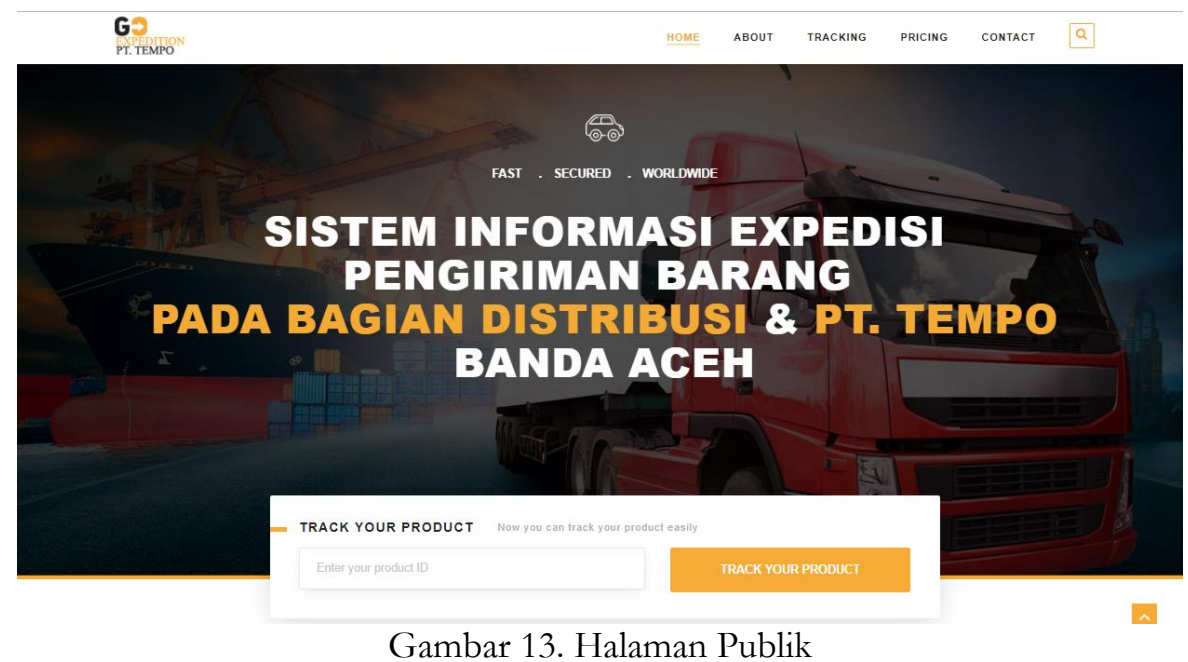

Berikut ini adalah hardware dan software yang dibutuhkan untuk menggunakan program sistem ekspedisi pengiriman barang, yaitu:

a. Hardware

Hardware yang dapat mendukung aplikasi ini memerlukan perangkat keras dengan spesifikasi:

1. CPU minimal pentium 3 dengan kecepatan $633 \mathrm{Mhz}$

2. Ram $256 \mathrm{MB}$

3. Hard disk minimal 1 GigaByte

4. Monitor

5. Keyboard dan Mouse

6. Printer

\section{b. Software}

Software yang mendukung aplikasi ini diantaranya:

1. Windows 7,8,10, Linux, Symbian, Android

2. Browser (Mozilla, Google Chrome)

3. Xampp.

\section{Kesimpulan}

Berdasarkan hasil pengamatan dan penulis dapat menarik suatu kesimpulan yang diantaranya adalah sebagai berikut:

a. Dalam mengolah data ekspedisi pengiriman barang, masih menggunakan pencatatan pada arsip atau buku, sehingga dapat mengurangi pelayan yang diberikan kepada ekspedisi pengiriman barang. Sebagai contoh, dalam proses pencarian data ekspedisi pengiriman barang membutuhkan waktu yang cukup lama, jika ekspedisi pengiriman barang yang datang jumlahnya cukup banyak maka waktu tunggu semakin lama, tentu saja hal ini akan membuat ekspedisi pengiriman barang merasa kurang dipedulikan dan kurang dilayani dengan baik. Data yang tersimpan dalam bentuk arsip atau buku, mempunyai resiko kehilangan dan kerusakan cukup tinggi, misal terbakar, terkena air, kertasnya robek dan hal lainnya. Data merupakan hal yang penting karena didalamnya terdapat data ekspedisi pengiriman barang, rawat laporan ekspedisi pengiriman barang dan hal-hal yang lain menyangkut laporan ekspedisi pengiriman barang. Untuk itu diperlukan sebuah solusi sistem yang terkomputerisasi untuk mengatasi masalahmasalah tersebut.

b. Berikut beberapa kelebihan yang didapat dari sistem yang telah terkomputerisasi dari sistem pencatatan pada arsip atau buku, antara lain: 
1. Untuk pengolahan dan pencatatan data dapat dilakukan dengan lebih baik, sehingga dapat mempersingkat waktu pengolahan data tersebut.

2. Proses pencarian data dapat dilakukan dengan cepat, sehingga waktu tunggu ekspedisi pengiriman barang menjadi singkat, maka setiap instansi membutuhkan layanan laporan ekspedisi pengiriman barang yang datang bisa mendapatkan pelayanan yang prima.

3. Memudahkan dalam pembutan laporan, baik laporan data ekspedisi pengiriman barang. Dengan fasilitas ini, maka laporan dapat dibuat dengan cepat, dan tepat serta rapi.

4. Dari keamanan data yang disimpan dalam sistem yang terkomputerisasi mempunyai tingkat keamanan yang tinggi karena dilengkapi dengan verifikasi pengguna (login user), sehingga hanya orang yang mempunyai hak akses saja yang dapat menggunakan.

5. Resiko kerusakan atau kehilangan data dalam sistem komputerisasi masih tetap ada, namun dalam skala yang relatif rendah. Untuk mengatasi hal ini dapat dilakukan backup data ke tempat penyimpanan lain selain harddisk komputer.

\section{Daftar Pustaka}

[1] Ahmad, A., 2012. Perkembangan teknologi komunikasi dan informasi: akar revolusi dan berbagai standarnya. Jurnal Dakwah Tabligh, 13(1), pp.137-149.

[2] Kristiyono, J., 2015. Budaya Internet: Perkembangan Teknologi Informasi Dan Komunikasi Dalam Mendukung Penggunaan Media Di Masyarakat. Scriptura, 5(1), pp.2330.

[3] Adinda, G.N., Rachman, A.N. and Ramdani, C.M.S., 2019. Implementasi Customer Relationship Management (CRM) Pada Aplikasi Monitoring Perusahaan Expedisi. SAIS | Scientific Articles of Informatics Students, 2(1), pp.49-53.

[4] Suhaimah, A., Triayudi, A. and Handayani, E.T.E., 2021. Cyber Library: Pengembangan Perpustakaan Online Berbasis Web Menggunakan Metode Prototyping (Studi Kasus Universitas Nasional). Jurnal JTIK (Jurnal Teknologi Informasi dan Komunikasi), 5(1), pp.41-48.

[5] Rajagukguk, J. and Sihombing, P., 2012. Optimalisasi Pemanfaatan Teknologi Informasi dan Komunikasi (ICT) sebagai Peluang di Era Globalisasi Ekonomi. In Prosiding Seminar Teknologi Informasi STMIK IBBI.

[6] Abdullah, M.A., Fitri, I. and Nathasia, N.D., 2020. Sistem Pendukung Keputusan untuk Menentukan Hasil Bisnis Pujasera Terbaik dimasa Pandemi Covid 19 dengan Metode Fuzzy Tahani dan Simple Additive Weighting (SAW) berbasis Website (Studi Kasus: Pujasera Hangout Salihara). Jurnal JTIK (Jurnal Teknologi Informasi dan Komunikasi), 5(1), pp.97-102.

[7] Pebrina, E.T., 2019. Pengembangan Aplikasi Pengolahan Data Pengiriman Barang Pada PT. Hati Mutiara. Insan Pembangunan Sistem Informasi dan Komputer (IPSIKOM), 4(2).

[8] Saputro, K.Z., 2018. Memahami ciri dan tugas perkembangan masa remaja. Aplikasia: Jurnal Aplikasi Ilmu-ilmu Agama, 17(1), pp.25-32. 
[9] Albab, P.U., Darussalam, U. and Winarsih, W., 2021. Sistem Informasi Penjualan Gitar Online. Jurnal JTIK (Jurnal Teknologi Informasi dan Komunikasi), 5(1), pp.21-25.

[10] Lubis, M.R., Susanti, E., Wirapraja, A., Siregar, M.N.H., Simarmata, J., Fadhillah, Y., Giap, Y.C., Abdillah, L.A., Purba, R.A. and Muttaqin, M., 2020. Pengenalan Teknologi Informasi. Yayasan Kita Menulis.

[11] Lussianda, E.O. and Munawir, M., 2021. Promotion Strategy On Decisions On Using J\&T Express Services, Pekanbaru. International Journal of Management Science and Information Technology, 1(1), pp.17-20.

[12] Kadafi, M., 2020. SISTEM INFORMASI PENGOLAHAN DATA TRANSAKSI PADA CV. GLOBAL TRANS SOLUTIONS. Jurnal Indonesia: Manajemen Informatika dan Komunikasi, 1(1), pp.1-8.

[13]Zulkarnain, Z., 2020. SISTEM INFORMASI PENGOLAHAN DATA PELANGGAN PADA CV. INDOPRINT BANDA ACEH. Jurnal Indonesia: Manajemen Informatika dan Komunikasi, 1(1), pp.28-34.

[14] Ardiansyah, T., 2020. SISTEM INFORMASI PEMESANAN TIKET PADA CV. GLOBAL TRANS SOLUTIONS. Jurnal Indonesia: Manajemen Informatika dan Komunikasi, 1(1), pp.9-19.

[15] Iqbal, T., 2019. Perancangan Repository Dengan Dukungan Open Archieve Initiative (Oai) Berbasis Open Source Menggunakan Codeigniter Dan Node. Js. Smart Comp: Jurnalnya Orang Pintar Komputer, 8(2), pp.57-62.

[16] Wali, M. and Ahmad, L., 2018. Perancangan Access Open Journal System (AOJS) dengan menggunakan Framework Codeigniter dan ReactJs. Jurnal JTIK Jurnal Teknologi Informasi dan Komunikasi), 2(1), pp.48-56.

[17] Yauma, A., Fitri, I. and Ningsih, S., 2021. Learning Management System (LMS) pada ELearning Menggunakan Metode Agile dan Waterfall berbasis Website. Jurnal JTIK Jurnal Teknologi Informasi dan Komunikasi), 5(3), pp.323-328.

[18] Irsandi, J.S., Fitri, I. and Nathasia, N.D., 2021. Sistem Informasi Pemasaran dengan Penerapan CRM (Customer Relationship Management) Berbasis Website menggunakan Metode Waterfall dan Agile. Jurnal JTIK Jurnal Teknologi Informasi dan Komunikasi), 5(4), pp.346-353.

[19] Wahyuddin, M.I., Aldisa, R.T., Fauziah, F. and Sholihati, I.D., 2021. Sistem Informasi Administrasi Kemahasiswaan dan Alumni (Smart Adma) dengan Metode Extreme Programming (XP). Jurnal JTIK (Jurnal Teknologi Informasi dan Komunikasi), 5(4), pp.425-429. 